
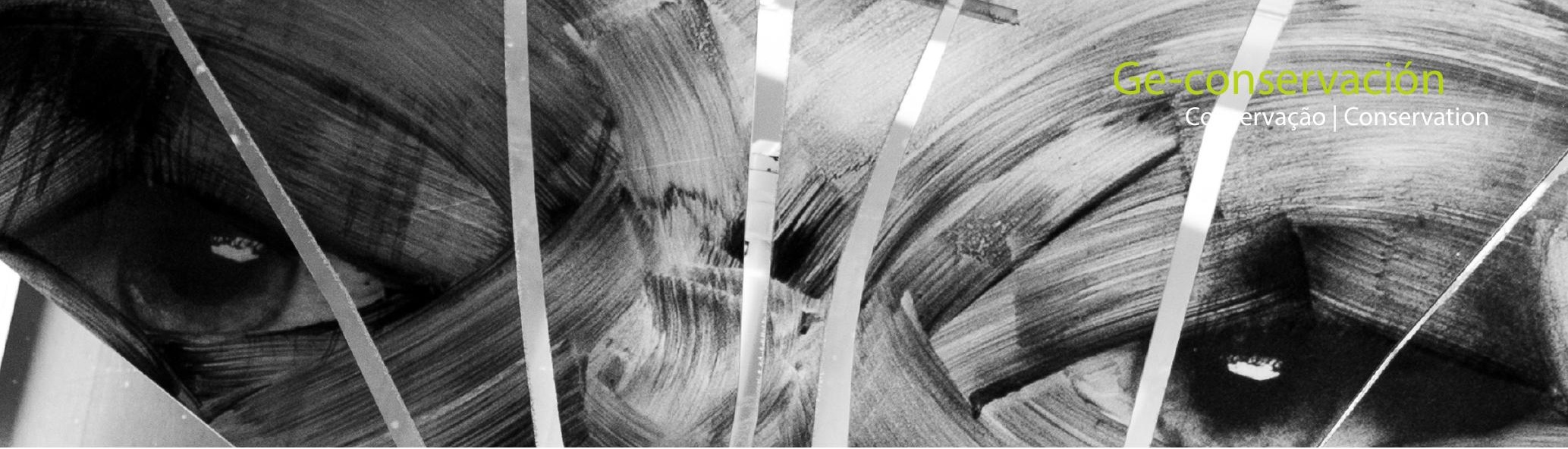

\title{
(des)Localizaciones y contexto. La transición del arte urbano desde la calle hasta su exhibición en centros de arte
}

\author{
Esteban Marín
}

Resumen: Breve reflexión a raíz del desmontaje, conservación y reubicación de un mural de gran formato (200m²) y de las experiencias expositivas en centros de arte contemporáneo y otros espacios institucionales de artistas provenientes del grafiti y el arte urbano. Estos dos casos nos servirán para explorar la relación entre las obras realizadas en el espacio público y cómo les afecta su deslocalización para ser introducidos en contextos expositivos o como piezas decorativas.

Palabras clave: arte urbano, localización, museo, centro de arte

\section{(de)Locations and context. The transition of urban art from the street to its exhibition in art centers}

Abstract: Brief consideration following the disassembly, conservation and relocation of a large-format mural $\left(200 \mathrm{~m}^{2}\right)$ and the exhibition experiences in contemporary art centers and other institutional spaces of artists from graffiti and urban art. These two cases will help us to explore the relationship between the works carried out in the public space and how their relocation affects them to be introduced in exhibition contexts or as decorative pieces.

Key words: urban art, location, museum, art center

\section{Introducción}

La irrupción de los llamados artistas urbanos en galerías, centros de arte contemporáneo y museos se ha ido produciendo de manera gradual hasta el punto de que estamos siendo testigos de la apertura de centros privados y proyectos institucionales o independientes que se denominan a sí mismos como museos de arte urbano. Siendo el término arte urbano algo ya de por sí muy cuestionado al haber sido asimilado por instituciones culturales y la administración pública, encontramos en la creación de estos espacios la constatación definitiva de su instrumentalización y posterior muerte. Ante un término tan devaluado como el "arte urbano" y que en muchos casos se antoja incorrecto para definir intervenciones artísticas comisariadas e institucionales, la deriva para encontrar el término adecuado que defina a estas obras y a estos artistas ya ha empezado. Por poner algunos ejemplos, tenemos a la Biennale de arte "Artmosphere" (Moscú) [1] que define a los artistas participantes como parte de la "Street Art Wave", el festival de grandes murales en medianeras "CALLELIBRE" (Viena) [2] se define a sí mismo como de "Urban Aesthetics" o, sin ir tan lejos, la feria URVANITY de Madrid [3] hablando del "Nuevo Arte Contemporáneo". 
Este baile de nombres y definiciones intenta huir del término "arte urbano" a toda costa, ya sea por encontrarlo erróneo, insuficiente o carente de valor (comercial). Del mismo modo, algunos proyectos abrazan el término arte urbano y lo integran en su discurso, como es el caso de los denominados "museos"; otros huyen de esta definición y lo relacionan con nuevos espacios y oportunidades. Los casos de los espacios como "Urban Nation Museum"(Berlín) de el "Museo de Arte Urbano Contemporáneo", futuro museo de Street Art en Ámsterdam o el nuevo Centro de Arte Urbano B-Murals en Barcelona, son los ejemplos más notables, y hacen suyo sin pudor el término arte urbano, aún no conteniendo ninguno de ellos arte urbano en absoluto, aunque sí puedan promoverlo o coleccionar obras realizadas por artistas urbanos.

Los artistas se ven frecuentemente atrapados en estas categorías que no les definen en absoluto. Las etiquetas como la de "artista urbano" son bidimensionales, planas e incapaces de mostrar la totalidad de la producción artística del sujeto.

Un cuadro pintado por un artista urbano es un cuadro pintado por un artista urbano y no una obra de arte urbano. Y no hay nada de malo en ello. Del mismo modo que no hay, por lo general, seres bidimensionales y no existe una única definición, que se suele quedar corta para hablar de cualquier individuo, así, los llamados artistas urbanos escapan de las categorías únicas para hacer gala de una multidisciplinariedad elogiable. Es por ello, que el término "museo de arte urbano" en sí mismo suele ser erróneo por definición y estos centros están repletos de cuadros y obras de estudio de artistas urbanos y/o piezas robadas y arrancadas del espacio público. En ambos casos, no se trata de arte urbano, ya sea por el tipo de pieza, dónde y para qué fue producida o por ser arrancada de su contexto para ser expuesta. ¿Significa eso que el arte urbano no puede ser exhibido en museos o centros de arte? El arte urbano que se extrae del contexto para el que se produjo (espacio público) y se exhibe en un museo se asemeja más a la taxidermia, a la cabeza del león abatido y expuesto a la vista como trofeo. Eso no significa que no se pueda disfrutar de los otros aspectos de la producción de un artista. Que no se pueda valorar la producción de estudio, cuadros, instalaciones, etc. de estos mismos artistas, pero no se pueden reconocer en su totalidad y se tendrá una visión parcial, con una de sus líneas de trabajo, sin la que se desarrolla en el espacio público. Guste o no, estos artistas llevan años moviéndose entre la calle, el estudio, los centros de exhibición y venta de arte. A los consumidores, gestores y comisarios, les toca empezar a presentar a estos artistas en su totalidad y hacerles tomar el lugar que tienen y la denominación correcta de cada una de sus facetas. Apoyar, para mostrar y promover el disfrute de todos los aspectos que conforman la producción del artista, debería ser una prioridad. Valorar a un artista solamente por su trabajo en el espacio público es despreciar el resto de su producción y discurso para caer en un elitismo cultural, que también existe en el arte urbano.

\section{Entre la calle y el centro de arte: Proyecto $12+1$}

En Junio de 2015 se inicia el proyecto $12+1$ en Sant Feliu de Llobregat y unos meses después lo haría en L'Hospitalet de Llobregat. Actualmente también se realiza en Barcelona y Sant Vicenç dels Horts. El proyecto $12+1$, que nace con la idea de mostrar las diferentes facetas de artistas jóvenes y en su mayoría considerados "urbanos" y cómo se mueven, entre la calle, el estudio y los centros expositivos. Cuenta entre sus filas con escritores de grafiti, ilustradores, diseñadores, artistas visuales y un sinfín de corrientes, técnicas y estilos. Aun así, al desarrollar parcialmente su trabajo en el espacio público, todos ellos son catalogados (erróneamente) dentro del arte urbano.

El proyecto fue diseñado no sólo para mostrar varias facetas del trabajo de los artistas si no que se abordó de una manera no invasiva con el entorno y abrazando la efimeridad de este tipo de intervenciones murales. Para llevarlo a cabo, que no se necesitaban muros sobre los que realizar murales con los que mostrar a los artistas. Solo era necesario contar con un solo espacio en el que cada artista pudiera intervenir. Un muro en el que crear una nueva obra, cada vez, eliminando así la anterior de manera continuada. Esto permite un comisariado y el beneplácito de la administración sobre el proyecto (que no supervisa las obras). Se establece una programación estable que muestre la cantidad de corrientes artísticas que pueblan las calles hoy en día. Cada edición tiene una duración a largo plazo, varios meses, y cuenta con varios participantes. Se cierra con una exposición colectiva en un centro de exposiciones cercano al muro que ha servido de soporte durante todo el año.

Esta metodología es especialmente relevante en el espacio de L'Hospitalet de Llobregat, donde se sitúa el km2 más densamente poblado de Europa (Longás,2019) en un entorno degradado en vías de ser gentrificado, debido a la apertura de la nueva línea de Metro que va al aeropuerto de Barcelona.

Es un proyecto que se autolimita y permite intervenir el espacio sin colonizarlo y mediante el arte, actuando en una zona en riesgo y generando, a su vez, una programación cultural estable que era esperada por vecinos y artistas, para usar el espacio en idénticas condiciones para todos ellos [4] [figuras1 y 2].

Es en la segunda parte del proyecto en la que se centra el presente análisis y en cómo sucede la transición de estos artistas al Centre d'Art Tecla Sala en Hospitalet de Llobregat al final de cada edición.

Este centro se sitúa a escasos 150 metros de la zona donde están los murales y el equipamiento artístico de referencia. Con programa educativo propio, cuenta con cientos de metros para realizar exposiciones y con el capital humano y el presupuesto necesario. 


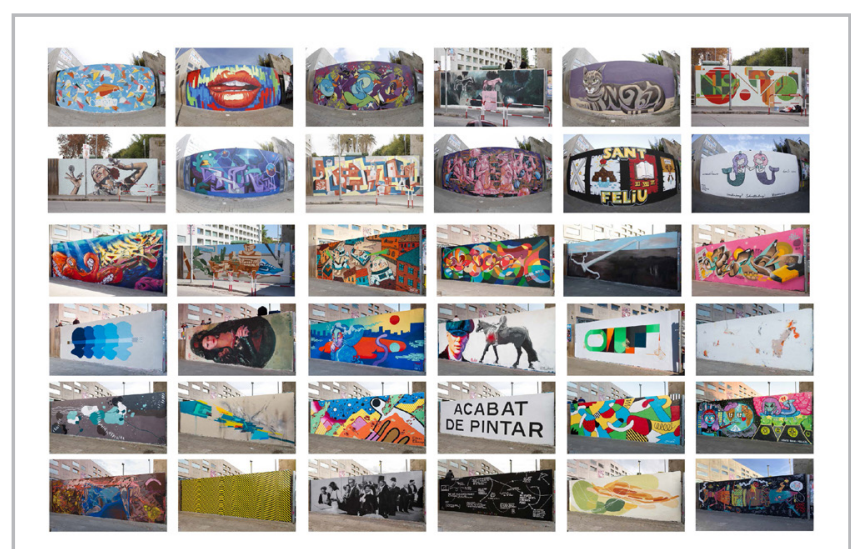

Figura 1.- Murales del proyecto $12+1$ Sant Feliu de Llobregat. 2015-2018. Foto: Alex Miró]

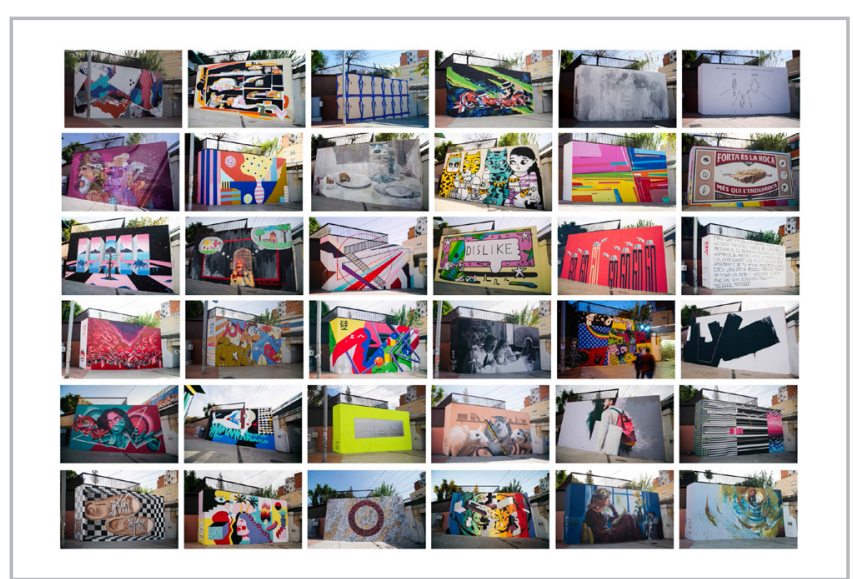

Figura 2.- Murales del proyecto $12+1$ L'Hospitalet de Llobregat 2015-2018. Foto: Clara Antón]

El Centro de Arte Contemporáneo Tecla Sala cuenta con una programación estable y de calidad, pero que prácticamente ningún vecino visita. Con una población superior a las 150.000 personas, pese a ser gratuito, el centro no supera habitualmente los 5 visitantes diarios si se excluyen las visitas concertadas con escuelas de la ciudad. Esta desconexión absoluta con el entorno que rodea al centro, a pesar de tener una programación de calidad, aunque esté anticuada, tiene una dirección artística en la que raramente se cuenta con exposiciones individuales con artistas que no sean contemporáneos, catalanes, hombres y mayores de cincuenta años [5]. Esto suponía un reto al que enfrentarse, al proponer que precisamente ese era el espacio idóneo para exponer los proyecto. Desde el inicio se creyó firmemente, que si no había representación de estas nuevas corrientes artísticas en el centro se debía proponer un proyecto que lo ayudase a avanzar en esa dirección para explorar nuevos caminos y reencontrarse con una ciudadanía más interesada en este tipo de exposiciones [6].

Muchos de los participantes del proyecto demostraban una dilatada carrera y han realizado exposiciones y murales por todo el mundo gozando de reconocimiento y apreciación. Artistas como Cinta Vidal, Medianeras Murales, Sue975, Etnik, Zurik o Mohammed L'Ghacham, han participado en estas exposiciones con un total de noventa y seis artistas locales e internacionales.

\section{Sucesión de pasos}

Se planteaban las primeras preguntas que afectan a la propia esencia de las obras. ¿Cómo se podría trasladar fielmente un proyecto de murales en el espacio público a un espacio tan elitista como es un centro de arte contemporáneo? ¿Cómo se puede trasladar la frescura y el "salirse de lo establecido" del arte urbano?

Es precisamente esa falta de rigor lo que hacía a estos artistas tan interesantes y lo que llevó a plantear la mejor manera de mostrar sus trabajos. En el caso de las exposiciones que retroalimentan este proyecto, las obras se dividieron en dos partes muy diferenciadas: una documental y otra con obra de estudio.

En la parte documental, que nunca ocupó más de un 25\% del espacio total, se mostraron textos e información para situar al público, así como las fotos de las intervenciones murales de los artistas participantes en orden cronológico. Estas fotografías estaban vinculadas a una aplicación de realidad aumentada que mostraba el vídeo individual del proceso de creación de cada una de las obras. La realidad aumentada permitía huir de las pantallas y los proyectores, así como, medir el número de reproducciones y hacer al público partícipe de la experiencia de ver al artista realizar su obra en el espacio público. Esta parte de la exposición se situó al inicio para contextualizar el proyecto, el espacio y a los artistas. [figuras 3 y 4 ]

Para la segunda parte de la exposición, se encontró una dificultad añadida. No sólo había que trasladar el carácter urbano de estos artistas a un espacio expositivo, sino que las diferentes líneas de trabajo, estilos y estéticas eran opuestas entre sí. Esto presentaba inconvenientes para encontrar un nexo común que uniera las piezas y dificultó

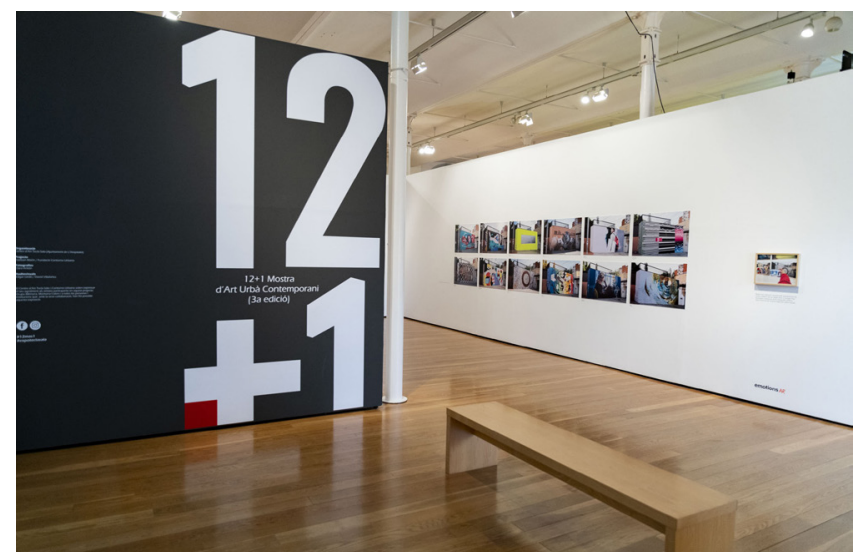

Figura 3.- Exposición 12+ Centro de Arte Tecla Sala, 2019. Foto, Clara Antón 


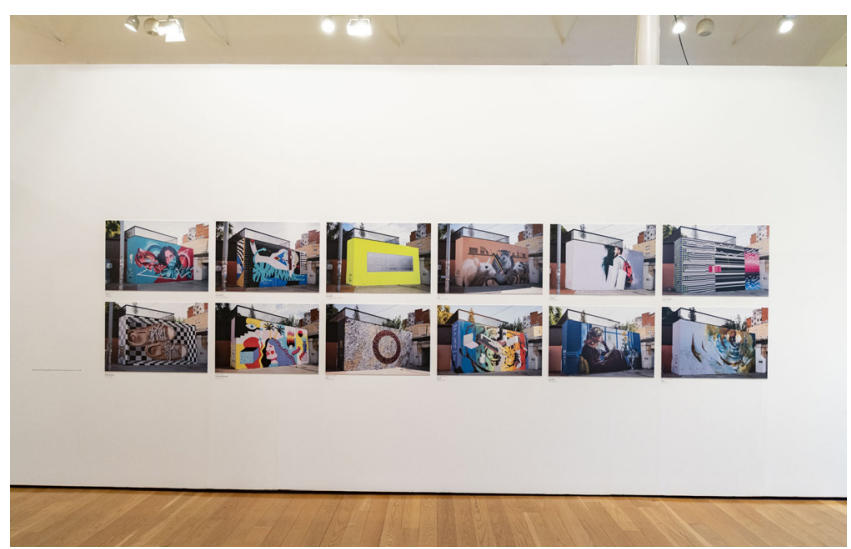

Figura 4.- Exposición 12+ Centro de Arte Tecla Sala, 2019.Foto, Clara Antón

la presentación y distribución de las obras. Tras un par de intentos fallidos, se llegó a la conclusión de que el único nexo que unía a estos artistas era un punto de vista desde el eclecticismo, porque a pesar de ser tan distintos todos eran considerados "artistas urbanos". Así que, la característica principal del proyecto fue la variedad de propuestas y el contraste que existe entre ellas, lo que las separaba, también las unía, si se situaban en un determinado orden.

Para realizar el proyecto expositivo se utilizó la metodología de la primera fase del proyecto y no se clasificaron por estilos o corrientes estéticas, sino que fueron intercalados para generar el máximo contraste posible entre ellos.

De igual modo, el desagrado manifiesto y la resistencia de los centros expositivos, ayudaron a explorar nuevas fórmulas para romper ligeramente el concepto de "caja blanca" donde se realizaba la exposición, para adaptarla a lo que los artistas querían mostrar. Esto sucedió de una forma gradual, al ir virando hacia una especie de "exposición de exposiciones" donde, al igual que en el espacio público, cada artista contaba con los mismos metros lineales y tenía total libertad para desarrollar su propuesta dentro de la propuesta general.

El criterio inicial fue mutando con el paso de los años hasta llegar a tener auténticas instalaciones, mucho más escultóricas, creadas para acompañar a las piezas de estudio. Además, estas instalaciones se diseñaron para ese espacio específico y siempre teniendo en cuenta el contexto - un centro de arte contemporáneo-y hasta a los "vecinos" de exposición.

Conforme se realizaban más exposiciones, se observó que al extrapolar algunos de los códigos de las intervenciones desde el espacio público - para adaptarse al lugar- se facilitaba también la transmisión de parte de las emociones vividas a un contexto totalmente diferente. Se transitaba por una línea intermedia en la que los artistas, para mostrar sus obras de estudio, intervienen también en el contexto, y esto se asemejaba a su manera de trabajar en la calle sin tener la necesidad de trasladar, literalmente, su trabajo pintado - un mural o una pieza de grafiti — a la sala de exposiciones con el consiguiente arranque. [Figuras 5 y 6 ]

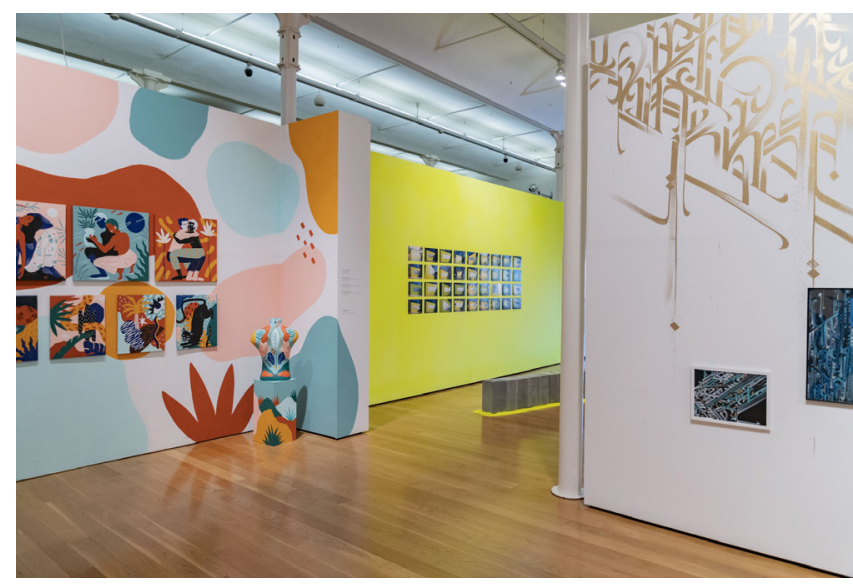

Figura 5.- Exposición 12+ Centro de Arte Tecla Sala, 2019. Instalaciones de Perriné Honoré, Sue975 y Asu de izquierda a derecha. Foto: Clara Antón

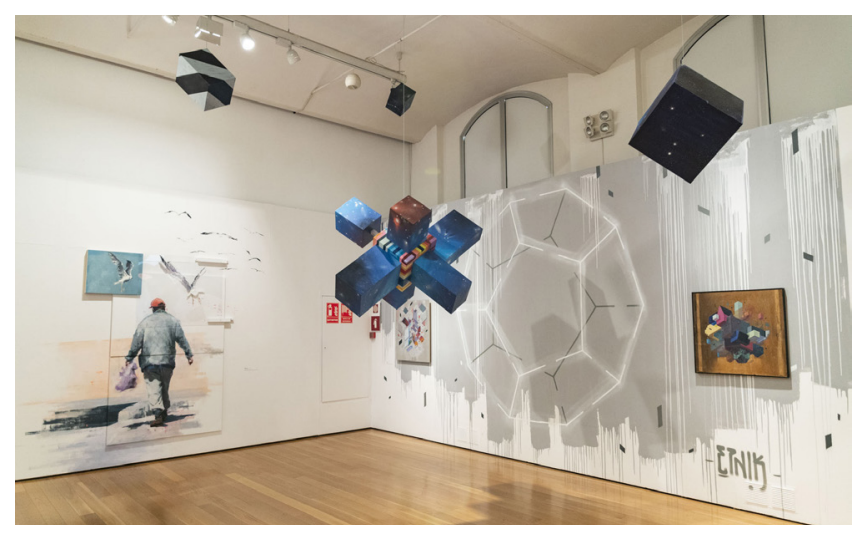

Figura 6.- Exposición 12+ Centro de Arte Tecla Sala, 2019. Instalaciones de Udane y Etnik de izquierda a Derecha. Foto: Clara Antón

Evidentemente esto es un camino que se ha ido trazando con la experiencia y que se perfecciona con cada nueva muestra, pero actualmente esta fórmula es la que mejor resultados ha dado y ha creado un alto grado de consenso entre artistas, público y la Fundación. No caer en lo redundante y fácil es sumamente complicado a veces y en este tipo de centros nadie intervenía las paredes blancas desde hacía años, si no era la primera vez.

¿Será que ante un muro en blanco es imposible resistirse? En este caso resultaba ser tan necesario que sin salirse de la línea marcada, sin manchar las paredes, habría sido mejor no hacer nada.

La posibilidad de intervenir el espacio en su totalidad se ha convertido en una condición indispensable, hasta el punto de rechazar la posibilidad de exponer en espacios municipales en los que haya que ceñirse a los muros en lanco y a los hilos de colgar. 
El resultado después de tres exposiciones en un Centro de Arte Contemporáneo es muy positivo, con una media de asistencia superior a la habitual, especialmente entre vecinos y residentes de la ciudad que, tras establecer un vínculo previo con una obra o con un artista, han querido conocer más sobre las otras facetas del autor.

\section{Murales y traslados: Mural Ciudad de las Rosas, Sant Feliu de Llobregat.}

El proyecto Kaligrafics funciona desde el año 1994 como colectivo de escritores de grafiti, no formal, y en 1999 se constituye como asociación sin ánimo de lucro. La sede de la entidad, se encuentra en el casal de jóvenes de la ciudad desde su constitución, un punto neurálgico de las actividades culturales del municipio. Como entidad, Kaligrafics es la más antigua en funcionamiento de toda Cataluña, está vinculada al "graffiti" y el hip-hop, que continúa gozando de un buen estado de salud y tiene nuevos miembros, más jóvenes que los miembros de la primera junta directiva.

\section{“Ciudad de las rosas" de Esteban Marín.}

En 2009 se realizó este gran mural institucional. Un encargo que en su momento fue un primer trabajo remunerado para el artista, con la ayuda que esto supone para poder desarrollar en el futuro más y mejores proyectos, y es un mural que no ha envejecido bien con los años. Surge de una propuesta del Ayuntamiento de Sant Feliu de Llobregat en 2008 por el derribo de un edificio que dejaría descubierta la fachada del Casal de Jóvenes de la ciudad. La idea era la de representar a través del tema elegido a la ciudad de Sant Feliu, que es conocida como la ciudad de las rosas por su tradición en el cultivo de esta flor, y que durante la guerra civil cambió su nombre a Rosas del Llobregat. Hay que tener en cuenta, que la ciudad nunca había tenido un mural de este tipo ni de estas dimensiones, por lo que se pensó en hacer algo muy característico. Esto resultó ser un acierto y llevó a la realización posterior de propuestas mucho más arriesgadas, en parte, gracias a esa primera gran obra, que fue "la ciudad de las rosas" ejecutada por varios artistas, en colaboración. [figura 7]

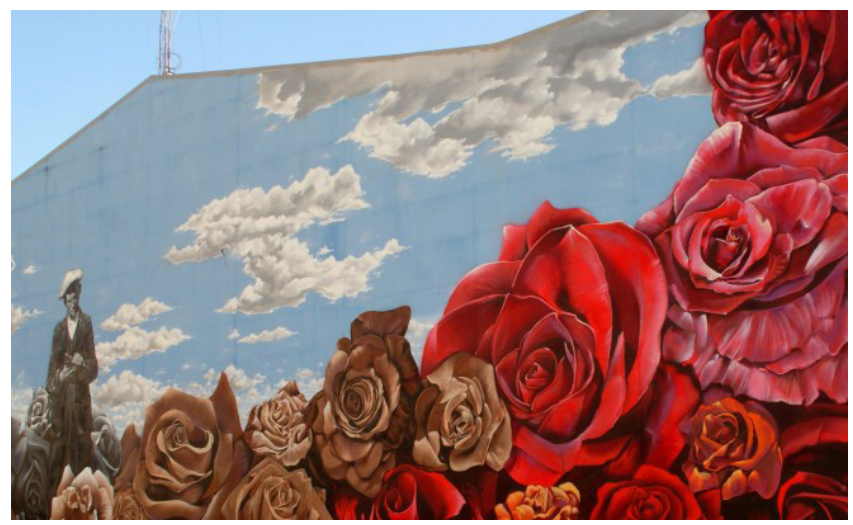

Figura 7.- Foto del mural "ciudad de las rosas"
El mural fue realizado sobre un conjunto de placas de fibrocemento instaladas en una subestructura metálica que cubría toda la fachada. Se pintó con aerosol y pintura de exterior, y con un barnizado de protección y el hecho de que no estuviese muy expuesto al sol ayudó a que se conservase en bastante buen estado durante años.

En 2016 el ayuntamiento decidió derribar el edificio para hacer un nuevo y más grande Casal de Jóvenes. Al ser un mural muy icónico y querido por la ciudad se realizó un pequeño estudio para desmontarlo y volver a instalarlo en otra localización. Esto fue posible gracias a que las placas de fibrocemento estaban unidas a la estructura con pequeños remaches fácilmente extraíbles. Aun así, durante el desmontaje alguna placa sufrió daños, especialmente durante su almacenaje y traslado al almacén municipal. El daño más común era la rotura de alguna de las esquinas al encontrarse el agujero del remache muy cercano al borde y debilitando la placa. Estas piezas tienen un tamaño máximo de dos metros de largo por sesenta centímetros de altura y son fácilmente apilables para su almacenaje. [figura 8]

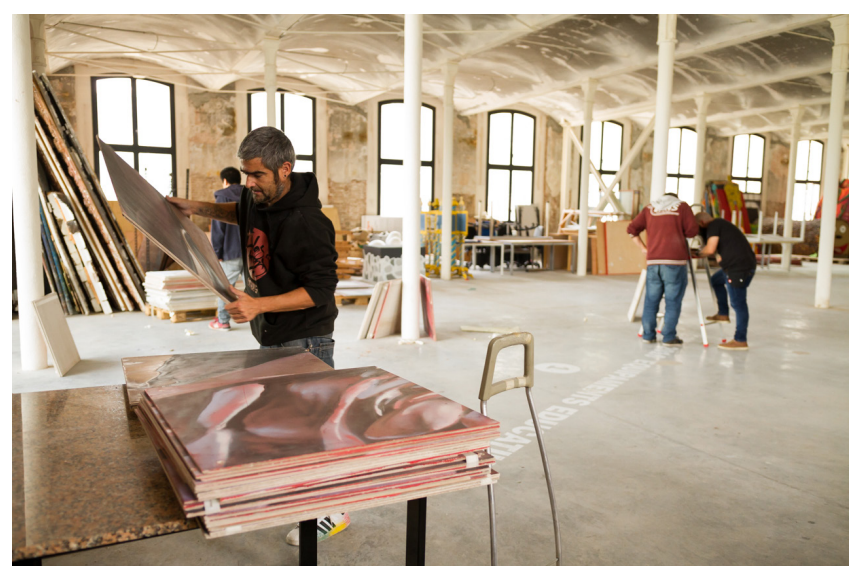

Figura 8.- Desmontaje y almacenamiento del mural. Foto, Alex Miró

En enero de 2018 uno de los autores del mural, el escritor de grafiti conocido como Treze muere a la edad de 31 años en Barcelona [7]. Algunos meses después se finaliza la construcción del nuevo edificio en el que no se dispone del mismo espacio para volver a colocar el mural, ya que la composición de la fachada ha cambiado completamente.

Durante los meses previos a la finalización del nuevo edificio se plantearon diferentes espacios para reubicar la obra, con el añadido que suponía el significado especial que le daba la muerte de uno de sus autores y debido a la presión por parte de la ciudadanía para su recuperación. Encontrar un espacio con las características adecuadas era una tarea complicada debido a la superficie de $200 \mathrm{~m}^{2}$ que tenía la obra. Se decidió colocar sólo la parte principal del mural que representaba a Pere Dot, el principal impulsor de la tradición de la rosa como imagen de la ciudad y que fue pintada por el artista Treze [8]. Pese a las reticencias iniciales de los autores —a la 
modificación de la disposición de las piezas que componen la obra - se consideró que era preferible esta solución, si ello permitía finalmente su exhibición pública. La propiedad intelectual de la obra pertenecía a los autores, pero no la propiedad del soporte que era del ayuntamiento.

Tras varias propuestas, que no conseguían consenso, la administración decidió unilateralmente su ubicación y por lo tanto su futuro. Al inaugurar el nuevo edificio saltan todas las alarmas, 8 de las placas que formaban la obra habían sido montadas y expuestas como decoración en las escaleras del edificio, sin consulta previa ni consentimiento expreso de los artistas. Al mismo tiempo, se notificó que algunas de las piezas serían utilizadas para decorar otros espacios y despachos de técnicos y políticos municipales, algo que ya había sido descartado cuando se empezaron a seleccionar las piezas. Tras la sorpresa inicial se informó de la decisión de denunciar la modificación de la obra por exponerse de forma fragmentada y sin consentimiento de los poseedores de la propiedad intelectual. Actualmente, la situación se encuentra en un punto muerto, en el que las piezas no pueden ser recolocadas sin consentimiento expreso, a riesgo de entrar en una dinámica de acciones judiciales que decidan una solución legal. Como única respuesta se ha llegado al bloqueo del proyecto por parte de la administración y a la imposibilidad de volver a colocar la parte principal del mural en homenaje a la ciudad y al autor fallecido.

Este ejemplo tan cercano ilustra bastante bien los riesgos del desmontaje y reubicación de piezas realizadas en el espacio público, muchas veces sin permiso de los autores, aunque en este caso existiera una buena predisposición por parte del artista.

La utilización por parte de las instituciones, ya sean museos privados o administraciones públicas, de este tipo de obras puede ser objeto de faltas contra la propiedad intelectual, que siempre pertenece al artista. No sólo eso, sino que, no hay que olvidar que es precisamente el riesgo de que estas obras sean arrancadas y reubicadas lo que puede dotar a esos fragmentos de un valor económico específico del que antes carecían. Poder mercantilizar y comerciar las piezas situadas en el espacio público - se realicen o no con permiso- es uno de los grandes problemas derivados de la proliferación de exposiciones en galerías, centros de arte y museos. Es evidente la dificultad para comercializar algo que no se puede vender como un producto tradicional y en el mercado, por este motivo, se observa la necesidad de encontrar soluciones de compromiso que faciliten la especulación artística y económica de esos bienes. La tendencia de llenar nuestras ciudades con intervenciones mastodónticas crea otra clase de mercado en el que el efecto revalorizador sobre ese espacio se utiliza como catalizador para reclasificar otros bienes —inmuebles — que sí pueden ser vendidos.

Probablemente muchos artistas se negarían a llevar a cabo obras desmontables si fueran conscientes de que sus fragmentos pueden llegar a ser separados sin su permiso, ya que lo que se lleva a cabo es una obra desmontable cuyos paneles por separado no tienen entidad propia como obra artística. En este caso la reubicación no se hizo de manera ilegal ni fue a parar a un museo donde se cobra entrada, pero fue una maniobra cuestionable y sin un criterio ético por parte de la administración. Ejemplos de malas prácticas, hay varios y muy mediáticos, con obras de Banksy (Chazan, 2019) o de Space Invaders (Sutton, 2017) son sobradamente conocidos. La realidad obliga a actuar con la máxima cautela en este tipo de procesos y empuja a la creación de modelos contractuales que reflejen los derechos de integridad material e intelectual de las obra.

\section{Conclusiones}

Con estos ejemplos recientes se pretende ilustrar tanto la correcta exposición de obras generadas por artistas con el perfil de "artistas urbanos", así como los peligros de la especulación y reubicación de obras que no han sido creadas para ser alejadas del espacio público, y mucho menos para ser obras decorativas y "de despacho". Ambas situaciones - exposición y reubicación de piezas- se dan cada vez con mayor frecuencia, tanto de forma acordada como ilícita y se ha convertido en una parte importante de todo lo que rodea al arte urbano y a sus movimientos derivados o paralelos.

La irrupción de las instituciones públicas en el "arte urbano" supone un riesgo altísimo y probablemente la deformación $y$, por lo tanto, la muerte de lo que ha hecho tan interesante este movimiento en las últimas décadas. Asimismo, los proyectos independientes y los artistas contribuyen a la asimilación por parte de las administraciones del arte urbano dentro de proyectos museísticos que alimentan una burbuja difícilmente sostenible y que ha dejado de ser interesante para muchos de los agentes involucrados desde sus inicios.

\section{Notas}

[1] Artmosphere, Biennale es la Bienal rusa que se celebran por primera vez en 2014 y 2016. Actualmente ha cambiado el nombre de Bienal de Street Art por el de Bienal de Street Wave, en respuesta a la opinión de que el arte callejero pertenece a la calle y, por lo tanto, no puede ser transferido y presentado adecuadamente en un espacio como es una galería. http://2018. artmossphere.com/ [consúlta: 30/08/19]

[2] CALLELIBRE, es un festival de estética urbana que muestra y fomenta a través de intervenciones artísticas el diálogo entre el público y los artistas. Las perspectivas culturales, las opiniones personales y artísticas se expresan libremente. https://www. callelibre.at/about [consúlta:30/08/19]

[3] Urvanity art, declaración de intenciones en favor de medios expositivos a través de los que explicar propuestas urbanas 
https://urvanity-art.com/manifiesto/ [consúlta: 30/08/19]

[4] Montana world blog, L'Hospitalet ofrece más información sobre el proyecto http://www.mtn-world.com/es/blog/tag/ lhospitalet-de-Ilobregat/ [consúlta: 30/08/19]

[5] Laura L. Ruiz, 07/02/2017, '“Contorno urbano', el muro de las reivindicaciones 'street art' en Barcelona" El Asombrario. https:// elasombrario.com/contorno-urbano-street-art-barcelona/ [consúlta 03/11/19]

[6] La colaboración con la dirección del centro no resultó fácil, negándose a mostrar obra de estudio de los artistas participantes y ofreciendo como alternativa mostrar solamente las fotos de los murales pintados en el proyecto, argumentando que las obras de estudio no podían ser expuestas por "su baja calidad artística". Durante el montaje del segundo año, fueron arrancadas varias piezas de la pared dos días antes de la inauguración. El público que quería visitar la muestra era invitado a entrar por una puerta trasera. Esto es sólo un ejemplos de la resistencia ofrecida por este centro de arte contemporáneo para exponer obras de "artistas urbanos". Situaciones similares se han dado en centros de exposiciones municipales en otras localidades. La resistencia a abrir la puerta a los artistas ha sido siempre una tónica general. A pesar de las malas experiencias se han conseguido comisariar nueve exposiciones en espacios institucionales en los últimos cuatro años.

[7] Relación de exposiciones individuales en el Centro de Arte Tecla Sala desde el 2014: Joaquim Chancho, 1943. Josep Maria Alcover, 1950. Gervasio Sánchez, 1959. Jiménez Balaguer, 19282015. Margarita Andreu, 1953-2013. Jaume Pitarch, 1963. Lluís Lleó, 1961. Pepe Espaliú, 1955-1993. Jaume Pitarch, 1963. Lluís Hortalà, 1959. Eugenio Ampudia, 1958.

En las exposiciones colectivas también predominan los hombres así como en las exposiciones individuales organizadas por el festival de videoarte LOOP.

[8] Montana World Blog, 29/01/18, "La belleza de la vida, Treze para siempre" "En su silenciosa batalla de casi cuatro años contra el cáncer, Treze, exprimió su potencial viajando a gran cantidad de ciudades por todo el mundo. Una lucha ejemplar que siempre trató de llevar con discreción para no alarmar a sus allegados". https://www.mtn-world.com/es/blog/2018/01/29/the-beautyof-life-treze-forever/ [consúlta: 03/11/19]

\section{Bibliografia}

CHAZAN, D. ( 26/01/19), "Banksy painting stolen from Bataclan" Telegraph, news. https://www.telegraph.co.uk/ news/2019/01/26/banksy-painting-stolen-bataclan/ [consúlta 07/09/19]

LONGÁS, H. (27/02/16) Menos de un kilómetro cuadrado para 43.000 vecinos. El País, A fondo. https://elpais.com/ elpais/2016/02/23/media/1456224524 967983.html [consúlta 08/09/19]
SUTTON, B. (07/07/2017), “Vigilantes Posing as City Workers Steal Street Art in Paris" Hyperalergic, In brief. https://hyperallergic. com/394562/vigilantes-posing-as-city-workers-steal-street-artin-paris/ [consúlta 07/09/19]

\section{Autor/es}

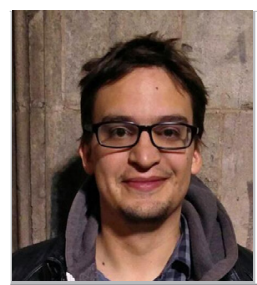

\section{Esteban Marín}

Contorno Urbano, project@contornourbano.com

Empieza a pintar graffiti en el año 2000 y se vincula al tejido asociativo del Baix Llobregat, ocupando desde entonces diferentes cargos en asociaciones de arte urbano en Sant Feliu, Cornellà y L'Hospitalet de LLobregat. El arte urbano despierta su interés para formarse como artista y realiza durante los siguientes años sus estudios en diseño gráfico e ilustración. En 2009 realiza su primer mural de gran formato y desarrolla su carrera artística. En 2015 funda el proyecto Contorno Urbano, que en 2017 se constituye como Fundación sin ánimo de lucro, en la cual ejerce de presidente y comisario desde sus inicios. 